\title{
Mice Lacking tPA, uPA, or Plasminogen Genes Showed Delayed Functional Recovery after Sciatic Nerve Crush
}

\author{
Lisa B. Siconolfi and Nicholas W. Seeds \\ Neuroscience Program and Department of Biochemistry and Molecular Genetics, University of Colorado Health Sciences \\ Center, Denver, Colorado 80262
}

\begin{abstract}
Axonal outgrowth during peripheral nerve regeneration relies on the ability of growth cones to traverse through an environment that has been altered structurally and along a basal lamina sheath to reinnervate synaptic targets. To promote migration, growth cones secrete proteases that are thought to dissolve cell-cell and cell-matrix adhesions. These proteases include the plasminogen activators (PAs), tissue PA (tPA) and urokinase PA (UPA), and their substrate, plasminogen. PA expression and secretion are upregulated in regenerating mammalian sensory neurons in culture. After sciatic nerve crush in mice, there was an induction of PA mRNAs in the sensory neurons contributing to the crushed nerve and an upregulation of PA-dependent activity in crushed nerve compared with sham counterparts during nerve regeneration. To further assess the role of the PA system during peripheral nerve regeneration, PA-dependent activity as well as recovery of sensory and motor function in the
\end{abstract}

Growth cones of regenerating peripheral neurons must migrate through a structurally altered injury site, around infiltrating cells, through a modified extracellular matrix (ECM), and along a residual basal lamina to reinnervate their synaptic targets. A potential means of promoting axonal outgrowth in this environment would be for the growth cones of regenerating neurites to use proteases, such as plasminogen activators (PAs), that are capable of degrading matrix molecules and cell adhesions. Tissue plasminogen activator (tPA) and urokinase plasminogen activator (uPA) cleave the proenzyme plasminogen to its active form, plasmin. Plasmin is a serine protease with a broad spectrum of substrates including most ECM molecules and cell-adhesion molecules, including neural cell adhesion molecule (NCAM) (Endo et al., 1998). Additionally, plasmin can activate several matrix metalloproteases (MMPs) (Murphy and Doherty, 1992) and growth factors, including transforming growth factor $\beta$ (TGF $\beta)$ and basic fibroblast growth factor (bFGF) (Saksela and Rifkin, 1990; Brauer and Yee, 1993; Munger et al., 1997). uPA and tPA

\footnotetext{
Received Oct. 31, 2000; revised March 1, 2001; accepted March 14, 2001.

This work was supported by grants from the National Science Foundation (IBN 9630458), the Spinal Cord Research Foundation (2081), and National Institutes of Health (NS09818) to N.W.S., and the National Institute of Child Health and Human Development (T32-HD07408) and the National Institute of Neurological Disorders and Stroke (T32-NS07083) to L.B.S. We are very grateful to Drs. Peter Carmeliet and Desire Collen for providing the initial breeding pairs of tPA and uPA knock-out mice, as well as to Drs. Keld Dano and Jay Degen for providing the plasminogen knock-out mice, and Dr. David Muir for the GAP-43 antibody. We also thank Susan Haffke for excellent technical assistance.

Correspondence should be addressed to Dr. Nicholas W. Seeds, Department of Biochemistry and Molecular Genetics, University of Colorado Health Sciences Center, 4200 East Ninth Avenue B-121, Denver, CO 80262. E-mail: Nicholas.Seeds@uchsc.edu.
}

Copyright (C) 2001 Society for Neuroscience $0270-6474 / 01 / 214348-08 \$ 15.00 / 0$ injured hindlimb were assessed in wild-type, tPA, uPA, and plasminogen knock-out mice. Protease activity visualized by gel zymography showed that after nerve crush, the upregulation of PA activity in the IPA and UPA knock-out mice was delayed compared with wild-type mice. Recovery of sensory function was assessed by toe pinch, footpad prick, and the toe-spreading reflex. All knock-out mice demonstrated a significant delay in hindlimb response to these sensory stimuli compared with wild-type mice. For each modality tested, the uPA knock-out mice were the most dramatically affected, showing the longest delay to initiate a response. These studies clearly showed that PAs were necessary for timely functional recovery by regenerating peripheral nerves.

Key words: tissue plasminogen activator; urokinase; plasminogen; nerve regeneration; sciatic nerve; functional recovery also demonstrate plasminogen-independent proteolytic activities, including the activation of a neuronal responsive growth factor, pro-hepatocyte growth factor/scatter factor (HGF/SF) (Mars et al., 1993), as well as the cleavage of fibronectin by uPA (McGuire and Seeds, 1990; Gold et al., 1992).

Various studies have documented the presence of PAs in neurons and PA system involvement in axonal outgrowth. PAs are secreted by cultured peripheral neurons and Schwann cells (Krystosek and Seeds, 1981, 1984); PA-dependent activity is localized to sensory neuron growth cones in culture (Krystosek and Seeds, 1984). Furthermore, the PA system is induced in developing murine embryonic dorsal root ganglia (DRG) and ventral motor neurons during the period of axonal outgrowth toward their peripheral targets (Sumi et al., 1992; Seeds et al., 1996). Murine DRG axons regenerate in vitro, and this process was coincident with a 75- to 165-fold increase in PA mRNAs during the period of maximal axonal outgrowth (Hayden and Seeds, 1996). In the accompanying report, we have shown that the plasminogen activator system was also induced in sensory neurons, after sciatic nerve crush in the mouse. PA mRNAs were elevated as early as 8 hr after sciatic nerve crush in spinal (L4-6) DRG sensory neurons contributing to the injured sciatic nerve, whereas PAdependent activity was increased at the crush site for up to $7 \mathrm{~d}$ after nerve injury. The increases in PA mRNAs and PAdependent enzymatic activities that occurred after peripheral nerve injury were coincident with nerve regeneration (Siconolfi and Seeds, 2001). These studies clearly demonstrated the induction of the PA system after nerve injury but did not assess whether recovery of sensory and motor function requires the reexpression of the PA system components during peripheral nerve regenera- 
tion. Therefore, this study investigated the functional consequences of the absence of tPA, uPA, or plasminogen on peripheral nerve regeneration. Using knock-out mice deficient in individual components of the PA system, our studies showed that these proteases were necessary for timely regeneration of peripheral sensory nerves and restoration of peripheral sensitivity and motor functions.

A preliminary report of some of these findings has appeared previously in abstract form (Siconolfi and Seeds, 1998).

\section{MATERIALS AND METHODS}

Surgery. Adult mice (C57BL6, C57BL6/129 outbred hybrid mice, tPA-/mice on a C57BL6 background, uPA - / - mice on a C57BL6/129J background, and plasminogen $-/-$ mice on a C57BL6/129J background and their $\mathrm{tPA}+/+$, uPA $+/+$, and plasminogen $+/+$ counterparts on the same genetic background (equaled wild-type mice including C57BL6) were anesthetized with a mixture of $160 \mathrm{mg} / \mathrm{kg}$ ketamine and $12 \mathrm{mg} / \mathrm{kg}$ rompun injected intraperitoneally. All surgical protocols were Institutional Animal Care and Use Committee approved. The area above the left lower thigh was shaved and sterilized with Betadine and 70\% ETOH. A $1 \mathrm{~cm}$ incision was made in the skin above the lower thigh between the gluteus maximus muscle and the biceps femoris muscle. The muscles were teased apart with scissors, and the sciatic nerve was exposed. For crush injury, the nerve was placed in a 1-mm-wide needle holder and crushed for $20 \mathrm{sec}$ (Glazner et al., 1993, 1994; Navarro et al., 1994). The holder was rotated $90^{\circ}$, and the crush was repeated at the same site. The nerve was replaced under the muscle, and the incision was sutured. The crush site for each animal was kept constant at $45 \mathrm{~mm}$ from the tip of the third digit by overlying a measured thread along the projection of the sciatic nerve. Completeness of the crush was established by examining for the loss of sensory and motor function in the hindlimb of the operated mice. Pinching the hindlimb digits and pricking the footpad without eliciting a foot withdrawal and vocalization was noted as loss of sensory and motor function (Devor and Govrin-Lippmann, 1979; Navarro et al., 1994; Verdú and Navarro, 1997). The absence of the toe spreading reflex and lateral leg extension when the mouse was gently lifted by the tail (Gutmann et al., 1942; Azzouz et al., 1996), as well as a total lack of hindlimb movement while ambulating, also indicated loss of sensory and motor function. For sham controls, the sciatic nerve of the right hindlimb was surgically exposed but no crush was made. Completeness of crush was also analyzed by examining axonal integrity in sham and crush sciatic nerve tissue sections using bright-field and phasecontrast microscopy (see Perfusion and tissue sectioning).

The saphenous nerve, which also innervates the two most medial digits of the hindleg, will normally branch after nerve crush into the denervated sciatic nerve zone. To prevent this distal branching and reinnervation, the saphenous nerve was surgically cut at the same time as nerve crush surgery (Navarro et al., 1994). A small incision was made on the medial thigh, and the saphenous nerve was lifted using the tip of needle and cut with a scalpel blade. The wound was closed using a 7-0 suture. For sham controls, an incision was made but the nerve was not cut.

Perfusion and tissue sectioning. Animals were killed with an overdose of pentobarbital $(130 \mathrm{mg} / \mathrm{kg}$, i.p.). Immediately after respiratory arrest, the mouse's thoracic cavity was opened, and the body tissues were fixed by cardiovascular perfusion with $4 \%$ paraformaldehyde buffered by $2 \mathrm{ml}$ of $20 \%$ heparin $/ 80 \%$ sodium nitrate pumped through a needle inserted into the left ventricle of the heart. Fixation was complete when the internal organs and extremities were bleached and the animal became rigid. Immediately after fixation, the intact left and right sciatic nerves were removed, and the tissue was immediately frozen in isopentane $\left(-30^{\circ} \mathrm{C}\right)$. Frozen tissue was embedded in O.C.T. compound (Miles Inc., Elkhart, IN). The crushed nerve and its uncrushed counterpart were mounted and cryostat sectioned together. The $12 \mu \mathrm{m}$ cross sections were picked up on frosted glass microscope slides (Fisher Scientific, Pittsburgh, PA). Sections were viewed with phase-contrast or bright-field condensers using a Zeiss research microscope.

Immunohistochemistry. Sections were also immunostained with rabbit anti-GAP-43 antibody. The sections were rinsed with PBS, treated with blocking solution (4\% goat serum $+0.3 \%$ Triton X-100 in PBS) for $1 \mathrm{hr}$ at room temperature, then reacted with a 1:1000 dilution of a rabbit anti-rat GAP-43 antibody (gift from Dr. D. Muir, University of Florida School of Medicine) at $4^{\circ} \mathrm{C}$ for $24 \mathrm{hr}$. After they were rinsed several times with PBS, the sections were incubated for $1 \mathrm{hr}$ at room temperature with a solution of goat anti-rabbit IgG Alexa Fluor 568 (1:150; Molecular Probes, Eugene, OR), then coverslipped with Vectashield (Vector Laboratories, Burlingame, CA). The sections were visualized using a Nikon Eclipse PCM2000 confocal microscope using a $60 \times$ objective, and images were collected with Simple PCI digital program.

Zymography. Gel zymography was adapted from the procedure described by Heussen and Dowdle (1980). Ten percent polyacrylamide-SDS gels were copolymerized with casein ( $1 \mathrm{mg} / \mathrm{ml}$; Sigma, St. Louis, MO) and plasminogen (2.5 U/ml; Chromogenix AB, Molndal, Sweden). Control gels were prepared similarly but without added plasminogen. Mice were killed by $\mathrm{CO}_{2}$ narcosis at several time points (unoperated, $3 \mathrm{hr}, 8 \mathrm{hr}$, $1 \mathrm{~d}, 3 \mathrm{~d}, 7 \mathrm{~d} ; n \geq 3$ at each time point) after crush surgery. One centimeter of sciatic nerve, including the crush site and the comparable site of its contralateral uncrushed counterpart, were removed and immediately homogenized in $10 \mathrm{~mm}$ Tris- $\mathrm{Cl}$, pH 6.8. Tissue was normalized for protein concentration using the Lowry method (Lowry et al., 1951). Serial concentrations of the homogenate and known amounts of tPA (Genentech, San Francisco, CA.) were loaded onto the gels and electrophoresed. After electrophoresis, the SDS was extracted from the gel using $2.5 \%$ Triton $\mathrm{X}-100$, and the gel was incubated for $16 \mathrm{hr}$ in $0.1 \mathrm{M}$ Tris, pH 8.1 , at $37^{\circ} \mathrm{C}$, followed by staining with $0.125 \%$ Coomassie Blue in $50 \% \mathrm{MeOH} / 10 \%$ acetic acid. Destaining with the same solvent revealed transparent zones of lysis against the dark protein background at 65 and $43 \mathrm{kDa}$ corresponding to tPA and uPA, respectively. The uPA band was blocked by $1 \mathrm{mM}$ amiloride, an inhibitor of uPA activity that was added to the $0.1 \mathrm{M}$ Tris buffer during the incubation at $37^{\circ} \mathrm{C}$. The proteolyzed bands were quantified using a Molecular Dynamics Computing Densitometer (Sunnyvale, CA), in which 0.8 IU recombinant tPA standard $=3000$ densitometric units.

Functional testing. Recovery of pressure and pain sensitivity was tested on awake mice by pinching the most distal portion of each digit on both hindlimbs (crushed and uncrushed counterpart) with forceps and also by pricking the plantar surface of each respective foot with sharpened forceps. Foot withdrawal and vocalization were recorded as positive responses indicative of recovery (Devor and Govrin-Lippmann, 1979; Navarro et al., 1994; Verdú and Navarro, 1997). Normally, when the mouse is lifted gently by the tail, the legs extend laterally and the digits spread, maximizing the space between them; recovery of this toe spreading reflex was also assessed. Positive responses indicative of initial recovery were recorded when the mouse displayed lateral movement of the hindleg accompanied by any foot flexure when lifted by the tail (Gutmann et al., 1942; Azzouz et al., 1996). All tests were performed each day after crush for up to $30 \mathrm{~d}$. All mice were tested before surgery to ensure that they all responded normally and that there were no differences in normal responses between the genetic backgrounds. For each group tested, $n=5$.

\section{RESULTS}

\section{Crush surgery verification}

To visually assess the extent of crush injury, cross sections of sham and crushed sciatic nerve from wild-type mice were examined by light microscopy. Figure 1 shows cross sections of crushed (Fig. 1A) and sham (Fig. 1B) nerve distal to the injury site $3 \mathrm{~d}$ after injury. Axons from the crushed sciatic nerve showed signs of degeneration. Collapsed axons were evident as dark solid structures. Irregular myelin sheaths were noticeable as having darker spots of myelin interspersed with lighter areas. There was an apparent increase in interaxonal space compared with the control tissue. Sham nerve showed healthy intact myelinated axons (with clear centers) distributed evenly within the nerve bundle. Myelinated axons of the sham nerve had a compact and regularly shaped myelin sheath. These images showed that the axons of the crushed sciatic nerve were deteriorated, whereas the sham sciatic nerve remained intact. Nerve sections were also assessed for neurofilament protein (NFP) reactivity using anti-NFP antibody. NFP production and axonal transportation decreases significantly after nerve injury (Greenberg and Lasek, 1988; Oblinger and Lasek, 1988). Completeness of the crush injury was demonstrated by the loss of NFP distal to the crush site (Siconolfi and Seeds, 2001). 

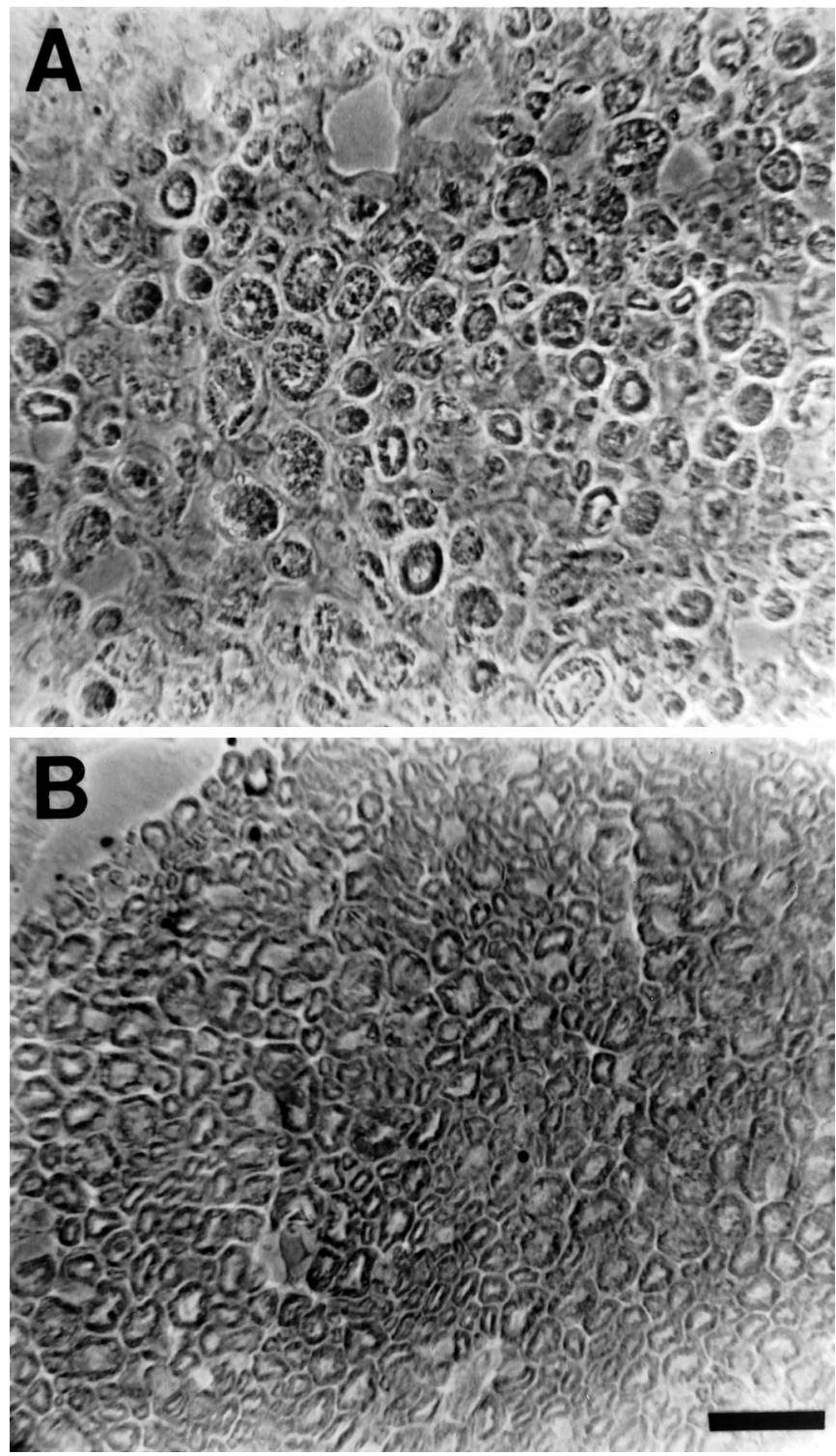

Figure 1. Degeneration of sciatic nerve in wild-type mice $3 \mathrm{~d}$ after crush injury. $A$, Phase-contrast microscopy shows sciatic nerve degeneration $3 \mathrm{~d}$ after nerve crush. Dark-filled and dark-speckled circles indicate collapsed axons. Degeneration of myelin sheaths appears as areas of dark myelin interspersed with clear areas of myelin. The degeneration also causes an increase in interaxonal space. $B$, Phase-contrast microscopy of sham nerve $3 \mathrm{~d}$ after surgery. Healthy axons appear as dark rings of myelin with clear centers. Nerve projections are uniformly spaced with no signs of axonal degeneration. Scale bar, $60 \mu \mathrm{m}$.

\section{PA activity after sciatic nerve crush}

The effects of an absence of tPA or uPA on the activity of the remaining PA in knock-out uPA (uPA-/-) and tPA (tPA-/-) mice after peripheral nerve injury were examined. Nerve tissue was dissected from around the crush site several times (unoperated, $3 \mathrm{hr}, 8 \mathrm{hr}, 1 \mathrm{~d}, 3 \mathrm{~d}, 7 \mathrm{~d}$ ) after injury in wild-type, tPA-/-, and $\mathrm{uPA}-/-$ mice, and PA activity was determined by densitometric analysis of zymography gels, such as one from $3 \mathrm{~d}$ after injury (Fig. 2). Wild-type mice showed a significant induction of both tPA- and uPA-dependent activities in crushed nerve compared with sham or unoperated nerve controls by $1 \mathrm{~d}$ after crush (Fig. 3A). The levels of crush-induced PA activities remained significantly elevated two- to threefold through $7 \mathrm{~d}$ after crush.

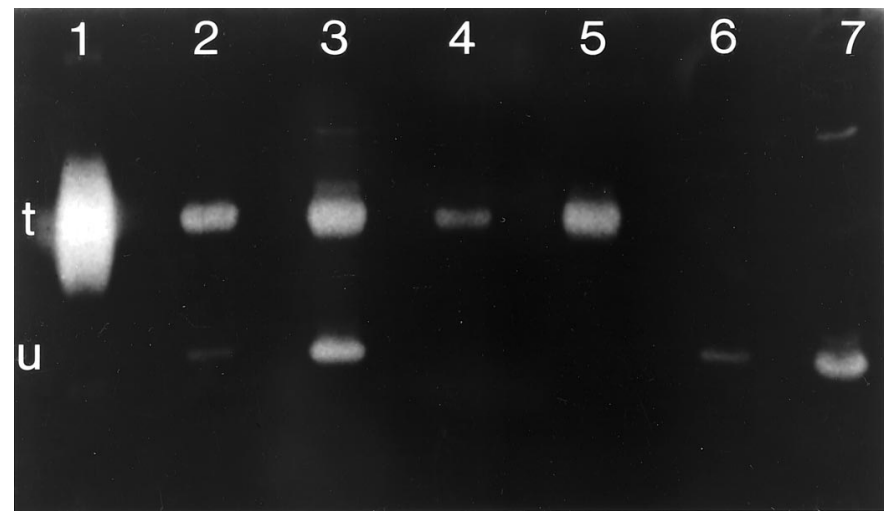

Figure 2. Gel zymography of PA-dependent activities in wild-type, tPA-/-, and uPA-/- mice $3 \mathrm{~d}$ after sciatic nerve crush. The PA proteolytic activity, as visualized by plasminogen-dependent casein zymography, shows a marked increase at the crush site compared with uncrushed sciatic nerve in both wild-type and knock-out mice ( $t, \mathrm{tPA} ; u, \mathrm{uPA})$. Lane 1, tPA standard, $0.8 \mathrm{mIU}$; lane 2, wild-type control nerve; lane 3, wild-type crushed nerve; lane 4, uPA-/- control nerve; lane 5, uPA-/- crushed nerve; lane $6, \mathrm{tPA}-1-$ control nerve; lane $7, \mathrm{tPA}-1-$ crushed nerve.

Activity of the lone PA, in tPA and uPA knock-out mice, followed a similar trend, except a significant increase in PA-dependent activity was not apparent until $3 \mathrm{~d}$ after crush (Fig. $3 B)(p=0.014$ for $\mathrm{tPA}-/-; p=0.016$ for $\mathrm{uPA}-/-)$. Both $\mathrm{tPA}-/-$ and $\mathrm{uPA}-/-$ mice demonstrated increased uPA- or tPA-dependent activity, respectively, in crushed nerve tissue through $7 \mathrm{~d}$ ( $p=0.028$ for tPA $-/-; p=0.05$ for uPA-/-). PA-dependent activity levels in unoperated tPA and uPA knock-out mice were comparable to PA activity levels of wild-type unoperated control animals. Also, in each knock-out condition, both sham and crushed nerve PA activity levels were similar to that in the wild-type mice at all times. These results demonstrated that knock-out mice showed a slight delay in upregulation of the activity of their lone PA after sciatic nerve crush. However, once induced, the lone PA in knock-out mice retained activity levels similar to the wild-type mouse crushed or sham sciatic nerve. Thus, the loss of one PA did not lead to a compensating upregulation of the activity level of the other PA.

\section{Axonal regeneration of sciatic nerve}

Sciatic nerve regeneration in the crushed nerve was demonstrated at the tissue level by the expression of growth-associated protein (GAP)-43. Regenerating neurons induce the synthesis and subsequent axonal transport of GAP-43 (Tetzlaff et al., 1989; Van der Zee et al., 1989); thus GAP-43 serves as a useful marker for axonal regeneration. Cross sections from 7 and $10 \mathrm{~d}$ sham and crush-operated nerve were immunostained with anti-GAP-43 antibody. Areas within $1 \mathrm{~mm}$ distal to the crush site displayed GAP-43 reactivity at $7 \mathrm{~d}$ (data not shown). At $10 \mathrm{~d}$, sections $\sim 1.3$ $\mathrm{mm}$ distal to the crush site show increased immunoreactivity, demonstrating that these axons were transporting GAP-43 (Fig. $4 A$ ), regenerating through the crush site of the injured sciatic nerve, and advancing into more distal areas. Sham nerve showed almost no reactivity (Fig. 4B). Longitudinal sections of crushed sciatic nerve at $10 \mathrm{~d}$ also displayed intense reactivity in areas distal to the crush (Fig. 4A, inset) compared with low levels of reactivity in sham nerve (Fig. $4 B$, inset).

\section{Functional recovery after sciatic nerve crush}

To assess the effect of an absence of tPA, uPA, or plasminogen on nerve regeneration, recovery of hindleg sensory and motor func- 

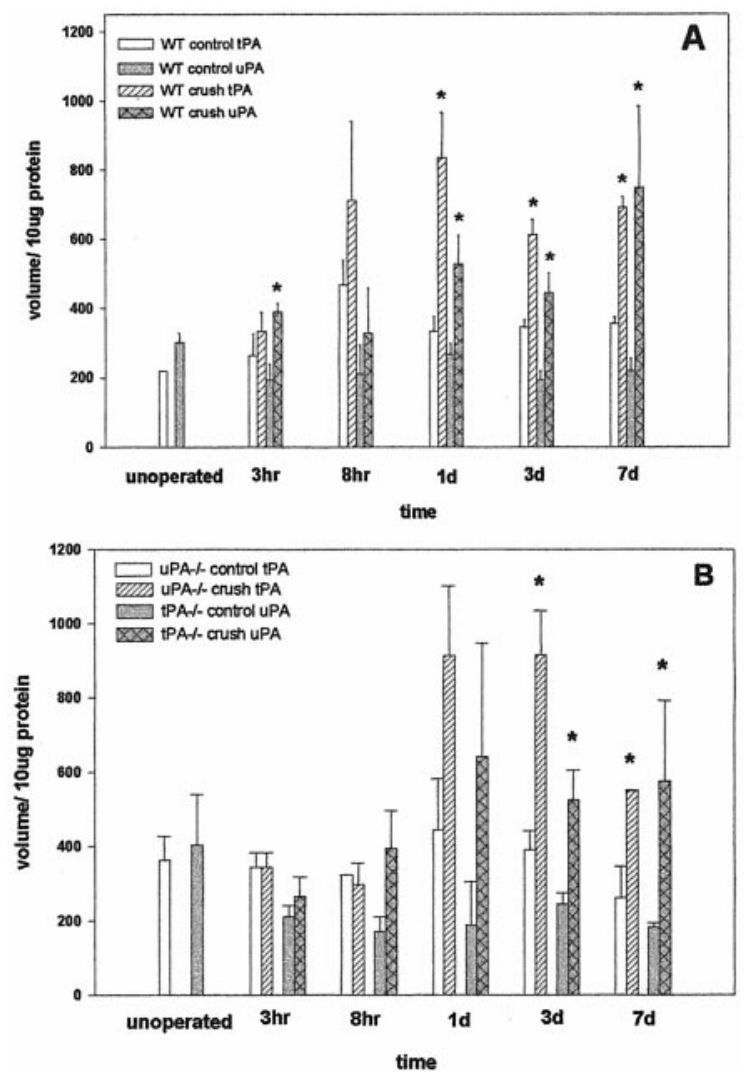

Figure 3. PA-dependent activity in crushed and control (sham + unoperated) sciatic nerve in wild-type and knock-out (tPA-/- and uPA-/-) mice. tPA (white bars) and uPA ( gray bars) activities were assayed by gel zymography at each of the time points. Lytic zones on zymographs were analyzed using known amounts of recombinant tPA standard (0.1 IU $\mathrm{rtPA}=375$ densitometric volumes). Values are expressed as the volume of lysis (mean \pm SEM; $n \geq 3$ ). Crushed nerve activity for each PA was compared with sham nerve activity (at each time point), and wild-type PA-activity was compared with knock-out PA activity by $t$ test analysis. $A$, In wild-type mice, uPA activity was elevated above sham at $3 \mathrm{hr}$, again at $1 \mathrm{~d}$, and stayed elevated two- to threefold through $7 \mathrm{~d}$ after sciatic nerve crush. tPA activity increased above sham nearly threefold by $1 \mathrm{~d}$ and remained elevated through $7 \mathrm{~d}\left({ }^{*} p \leq 0.05\right)$. $B$, In tPA $-/-$ and uPA-/mice, uPA- and tPA-dependent activity in crushed nerve increased significantly above activity levels in sham nerve by $3 \mathrm{~d}$ after injury and remained elevated two- to threefold through $7 \mathrm{~d}\left({ }^{*} p \leq 0.05\right)$. There were no significant differences between PA-dependent activity levels of wildtype and knock-out mice. However, there was a $2 \mathrm{~d}$ delay compared with wild type in crush-induced tPA- and uPA-dependent activity in both the $\mathrm{uPA}-/-$ and $\mathrm{tPA}-/-$ knock-out mice, respectively.

tion was assayed after sciatic nerve crush using the procedures of Devor and Govrin-Lippmann (1979) and Navarro et al. (1994). Recovery was analyzed by three different modalities. The tests involved (1) pricking the plantar surface of the hindpaws with sharpened forceps and (2) pinching the digits of the paw to elicit a foot withdrawal and vocalization. Foot withdrawal and a vocalization were recorded as positive responses indicative of sensitivity recovery. Sciatic sensory and motor nerve regeneration was also judged by the (3) reappearance of the toe-spreading reflex. Before surgery, all mice (wild type and knock-outs) showed equal sensitivity and response on each test. After crush injury, responses were totally abolished in the injured hindlimb. To control for variations in performance between different strains of mice, the wild-type group consisted of C57BL6 pure breds, tPA $+/+$, $\mathrm{uPA}+/+$, plasminogen $+/+$, and heterozygous littermate mice on
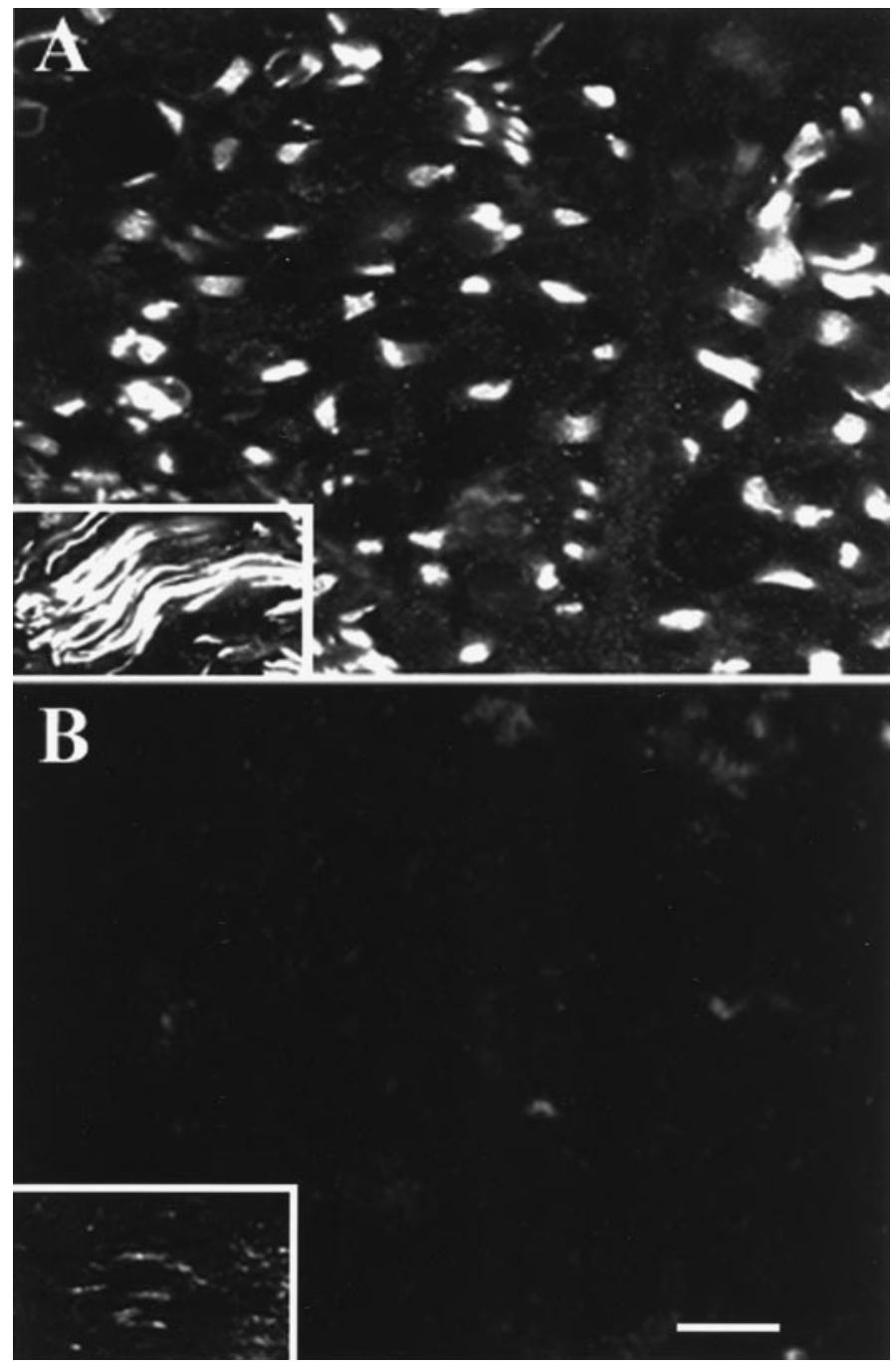

Figure 4. Immunohistochemical analysis using GAP-43 antibody shows axonal regeneration of crushed sciatic nerve. Ten days after crush surgery, nerve sectioned distal to the crush site and sham nerve were immunostained with GAP-43 antibody as a marker for regeneration. $A$, Cross section of crush nerve $\sim 1.3 \mathrm{~mm}$ distal to the crush site shows extensive GAP-43 reactivity compared with sham $(B)$. A, Inset, Longitudinal section of crushed nerve at area distal to crush also displays a high level of GAP-43 reactivity. B, Inset, Longitudinal section of sham nerve displays very low levels of GAP-43 reactivity. Scale bar, $10 \mu \mathrm{m}$.

a C57BL6/129J hybrid background. These mice did not differ from each other in performance on any of the tasks before and after surgery (data not shown).

For each test, we examined the time taken for the injured hindlimb to show any degree of a response to the stimulus. A measure of time to initial response would demonstrate any delays that might occur because of a lack of one of the proteases during the process of axonal regrowth across the injury site and subsequent reinnervation of the hindleg, as opposed to events involved in specific synaptic organization of reinnervated target receptors. Therefore, a positive response to the stimulus was indicative of general reinnervation of the hindlimb. Each test was analyzed statistically using $t$ tests to compare each knock-out condition separately with the wild-type mice. Results were significant when $t$ test yielded $p \leq 0.05$.

Response to footpad prick was significantly delayed in $\mathrm{UPA}-/-$ and $\mathrm{tPA}-/-$ mice compared with the wild type (Fig. 5) (tPA-/-, 


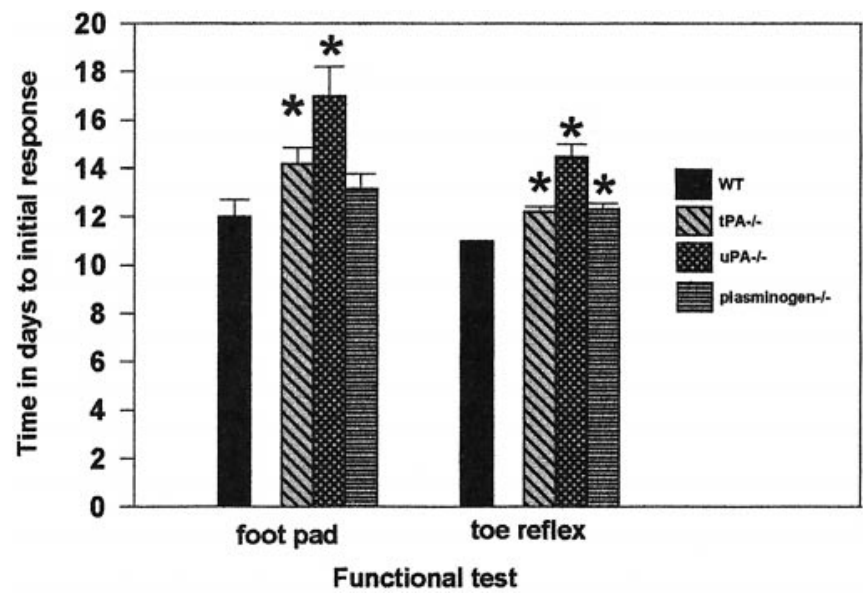

Figure 5. Recovery of sensory and motor functions after sciatic nerve crush. Using sharpened forceps, a prick was given to the footpads of wild-type and knock-out (tPA-/-, uPA-/-, and plasminogen-/-) mice after sciatic nerve crush. The amount of time (in days) to elicit an initial response, as shown by a vocalization and foot withdrawal, was recorded. tPA- - and $\mathrm{uPA}-/-$ mice were significantly delayed compared with wild-type mice on the footpad test. Plasminogen-/- mice were comparable with their wild-type counterparts. Time (in days) of the first indication of a return of the toe-spreading reflex was also noted by examining for lateral extension of the hindlimb accompanied by a foot flexure. Return of the toe-spreading reflex was significantly delayed for all knockout mice compared with wild-type mice. For each test, uPA-/- mice were the most adversely affected (* $p \leq 0.05 ; n=5)$.

$p=0.05 ; \mathrm{uPA}-/-, p=0.007)$. uPA $-/-$ mice took $3-5 \mathrm{~d}$ longer than wild-type mice to show an initial response, whereas tPA-/mice showed a delay of $\sim 1-3$ d compared with wild-type mice. Plasminogen $-/-$ mice were not significantly different from wildtype mice $(p=0.237)$, showing no appreciable delay when tested for footpad response.

Return of the toe-spreading reflex was also affected in each of the knock-out mice (Fig. 5). uPA-/- mice showed a delay in response of 4-5 d compared with wild-type mice. tPA-/ - and plasminogen -/- mice were slower than wild-type mice, by 1-2 d, to show a response. Time delays were significant for tPA-/$(p=0.008), \mathrm{uPA}-/-(p \leq 0.001)$, and plasminogen $-/-(p=$ $0.004)$ mice compared with wild-type mice. Again, uPA - /- mice showed the greatest delay, whereas $\mathrm{tPA}-/-$ mice and plasminogen $-/-$ mice showed a similar delay.

Toe pinch was analyzed in two parts: the amount of time taken to show an initial response to pinch in each digit and the amount of time taken to elicit a response in all five digits. Responsiveness in digits (except for the second most medial digit) was significantly delayed in each knock-out condition when compared with the wild-type mice [Fig. 6, Table 1 (for $p$ values)]. uPA-/- mice were the most affected. tPA $-/-$ and plasminogen $-/-$ mice exhibited significant delays compared with the wild-type mice, but the effect was less severe than recorded in the $\mathrm{uPA}-/-$ mice. Digit functional recovery occurred in the medial to lateral direction for all mice. Additionally, the time required for total recovery of all digits was recorded. The responsiveness of all digits indicated return of the sciatic nerve to the most distal areas of innervation. This was measured as the time when each digit of the hindpaw elicited a positive response on pinch. For each group of knock-out mice, responses were slower than wild-type mice, with uPA-/mice being most impaired ( $\mathrm{uPA}-/-, p=0.016$; $\mathrm{tPA}-/-, p=$ 0.018 ; plasminogen $-/-, p=0.032$ ), whereas $\mathrm{tPA}-/-$ and plasminogen $-/-$ mice showed similar delays (Fig. 7).

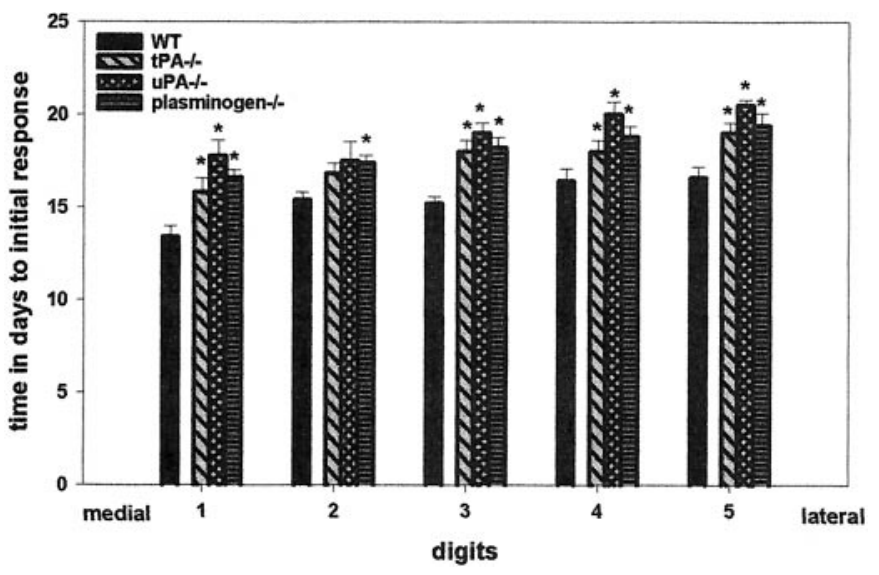

Figure 6. Recovery of response to pinch in hindfoot digits after sciatic nerve crush. Wild-type mice and knock-out mice (tPA- $-1-$, uPA $-/-$, and plasminogen $-/-$ ) received a pinch to the distal portion of each hindfoot digit using forceps. A vocalization and foot withdrawal were noted as a positive response. Time (in days) to elicit an initial response was recorded for each digit. Knock-out mice displayed an initial response to pinch that was significantly delayed compared with their wild-type counterparts for each digit (except digit 2). uPA - /- mice demonstrated the longest delay. Digits are labeled 1 through 5 , with 1 the most medial and 5 the most lateral digit ( $\left.{ }^{*} p \leq 0.05 ; n=5\right)$.

After crush injury, all mice dragged the injured hindleg and lost the ability to use the leg for ambulating. Although specific gait tests were not administered, use of the hindleg for some walking motions was generally regained. Wild-type mice appeared to begin using the injured hindleg 1-4 d earlier than the knock-out mice. Wild-type mice began showing signs of ambulatory motions (i.e., holding the leg under the torso in a walking position, less dragging of the injured leg, supporting body weight on the injured leg) with the injured hindlimb $\sim 10 \mathrm{~d}$ after crush injury. Plasminogen and tPA knock-out mice began to use the injured hindlimb for ambulating $\sim 12 \mathrm{~d}$ after crush, whereas $\mathrm{uPA}-/-$ mice were observed using the injured hindleg for gait approximately $14 \mathrm{~d}$ after crush (data not shown). These observations and the results of the sensitivity recovery tests demonstrated that an absence of tPA, uPA, or plasminogen adversely affected functional outcome after peripheral nerve injury.

\section{DISCUSSION}

This study showed that the PA system was necessary for timely recovery of sensory and motor functions in the hindlimb after

Table 1. $p$ value results of individual digit pinch tests

\begin{tabular}{llll} 
& $\begin{array}{l}\mathrm{tPA}-/- \\
(p \text { value })\end{array}$ & $\begin{array}{c}\mathrm{uPA}-/- \\
(p \text { value })\end{array}$ & $\begin{array}{c}\text { Plasminogen }-/- \\
(p \text { value })\end{array}$ \\
\hline $\begin{array}{lll}\text { Digit 1 } \\
\text { (most medial })\end{array}$ & 0.035 & $\leq 0.001$ & 0.002 \\
Digit 2 & 0.083 & 0.079 & 0.016 \\
Digit 3 & 0.005 & $\leq 0.001$ & 0.003 \\
Digit 4 & 0.05 & 0.008 & 0.028 \\
Digit 5 & 0.018 & 0.016 & 0.032 \\
(most lateral) & & &
\end{tabular}

$\overline{\text { Wild-type and knock-out mice (tPA-/-, uPA-/-, plasminogen-/-) were tested }}$ for functional recovery of digits after sciatic nerve crush, using forceps to pinch individual digits of the hindfoot. Foot withdrawal and vocalization were recorded as a positive response. Time in days taken to elicit an initial response to the test was noted and is illustrated in Figure 5. Results were analyzed using $t$ test analysis to compare each knock-out group with its wild-type counterpart (significant when $p \leq$ $0.05 ; n=5)$. 


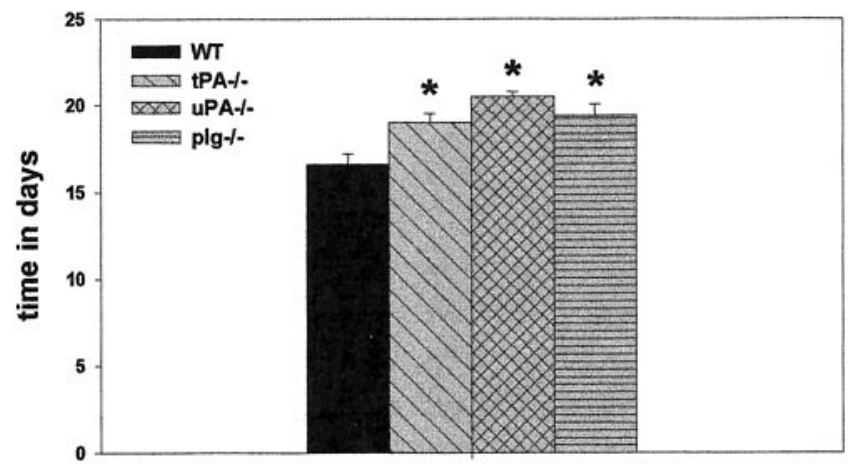

genetic background

Figure 7. Total recovery of stimulus response in all digits after sciatic nerve crush in wild-type and knock-out (tPA-/-, uPA-/-, and plasminogen-/-) mice. A toe pinch was given to each hindfoot digit and time (in days) to elicit a response in all five digits was recorded. A positive response occurred when toe pinch elicited a vocalization and foot withdrawal. All knock-out mice showed significant delays for time taken to show a positive response in all digits compared with their wild-type counterparts. uPA $-/-$ mice were the most severely impaired $\left({ }^{*} p \leq 0.05\right.$ compared with wild type; $n=5$ ).

peripheral nerve injury. These results augmented our previous findings that the PA system was induced after sciatic nerve injury and supported the hypothesis that the PA system facilitates peripheral nerve regeneration.

Analysis of PA-dependent activity in knock-out mice showed that the lone PA activity was comparable with wild-type PA activity after nerve crush and under sham and unoperated conditions. The lone PA activity in the $\mathrm{PA}-/-$ and uPA-/- knockout mice was upregulated after nerve crush to levels similar to wild-type mice, except induction was delayed $\sim 2 \mathrm{~d}$. Although wild-type mice increased activity of both tPA and uPA by $1 \mathrm{~d}$ after crush, knock-out mice did not show a significant increase in activity of their remaining PA until $3 \mathrm{~d}$ after nerve crush. The similarity between the upregulation of activity in the wild-type and knock-out conditions suggested that the expression of the lone PA did not compensate for the loss of the other PA. The delay in PA induction, however, can be caused by reactive cells (i.e., neutrophils, macrophages, and fibroblasts) that respond early to the injury. In the companion paper (Siconolfi and Seeds, 2001), we showed reactive neutrophils and macrophages present at the crush site by $1 \mathrm{~d}$ after injury. These cells, many of which express a PA system component, may use PA proteolytic activity for migration and other cell-specific functions (Eaton et al., 1984; Heiple and Ossowski, 1986; Kung and Lau, 1993; Schafer et al., 1994; Rao et al., 1995; Kindzelskii et al., 1996; Shetty et al., 1996; Tyagi et al., 1998). Absence of a specific PA may affect the normal migration and function of these cells in response to injury.

The delay in PA-dependent activity induction after nerve crush suggested that $\mathrm{uPA}-/-$ and $\mathrm{tPA}-/-$ mice might have retarded nerve outgrowth after injury and thus delayed functional recovery. Our previous studies demonstrating PA induction after peripheral nerve injury suggest that PA proteolytic activity may be needed for nerve regeneration (Siconolfi and Seeds, 2001). Thus, the absence of a PA component in this study resulted in a decrease of proteolytic activity that might be necessary to digest ECM or to release the growth cones of the regenerating neurons from cell and matrix contacts that impede axonal outgrowth.

Delayed recovery in $\mathrm{tPA}-/-$ mice may also be attributed partially to a loss of Schwann cell functions. Schwann cells that primarily express tPA (Kalderon, 1984; Krystosek and Seeds, 1984; Clark et al., 1991) migrate ahead of regenerating axons and provide both a favorable substratum and guidance clues for regeneration (Son and Thompson, 1995; Torigoe et al., 1996). These changes in Schwann cell morphology and migration may require tPA proteolytic activity. Therefore, the absence of tPA might compromise the environmental remodeling activities of Schwann cells necessary for nerve regeneration.

The absence of plasminogen also affected functional recovery. Plasmin would promote axonal regeneration by cleavage of growth cone cell-cell and cell-matrix contacts, as well as activate MMPs to recruit further proteolytic activity. Plasmin may also promote regeneration by activating latent matrix-bound growth factors, including latent TGF $\beta$ and bFGF (Saksela and Rifkin, 1990; Brauer and Yee, 1993; Odekon et al., 1994; Munger et al., 1997). Research has suggested that release and activation of these growth factors may be necessary to stimulate and maintain nerve regeneration. TGF $\beta$ promoted migration of neural crest cells during embryonic development and stimulated proliferation of cultured Schwann cells (Raivich and Kreutzberg, 1993; Rogister et al., 1993). bFGF promoted axonal outgrowth of chick neurons during development and promoted survival of adult rat retinal ganglion cells after optic nerve transection. bFGF also had a strong mitogenic effect on cultured Schwann cells (Sievers et al., 1987; Raivich and Kreutzberg, 1993; Perron and Bixby, 1999). Thus, plasmin activation of growth factors may be needed for successful nerve regeneration.

Interestingly, plasminogen $-/-$ mice were not different from wild-type counterparts when tested for response to footpad prick. The pinprick test is considered a nociceptive response (Verdú and Navarro, 1997). Nociceptive neurons, carrying pain and temperature information, are small-diameter sensory neurons, and they regenerate faster than large-diameter sensory neurons such as those innervating muscle spindles (Navarro et al., 1994). The small sensory neurons might be less dependent on plasminogen for regeneration than the large sensory neurons.

An impaired inflammatory response might contribute to the delay in recovery and the upregulation of PA-dependent activity, especially in the uPA-/- mice, which have a compromised immune system. Introduction of nonlethal pathogens in $\mathrm{uPA}-/-$ mice showed that these knock-outs were unable to mount an adequate inflammatory response. Specifically, the mice could not recruit sufficient mononuclear phagocytes, neutrophils, and lymphocytes (Carmeliet and Collen, 1996). In addition, stimulated macrophages from uPA $-/-$ mice lacked plasminogen-dependent breakdown of ${ }^{125}$ I-fibrin (Carmeliet et al., 1994). This impairment in the inflammatory response probably contributed to the delayed regeneration, because the inflammatory cells are important for clearing debris at the injury site, Wallerian degeneration, and stimulating the regeneration process (Hall, 1989; Fawcett and Keynes, 1990; Avellino et al., 1995).

The uPA-/- mice were the most severely impaired for recovery of function by all sensory stimuli, whereas tPA-/- and plasminogen $-/-$ mice showed very similar rates of recovery. This finding strongly suggested that uPA also has plasminogenindependent activities that are very important for nerve regeneration. Known plasminogen-independent activities of uPA have been demonstrated. In sensory neurons during neurite outgrowth in culture (McGuire and Seeds, 1990) and in transformed chick cells (Quigley et al., 1987), uPA directly cleaved extracellular matrix molecules, including fibronectin (Gold et al., 1992). uPA 
also activated MMP-2, a protease with substrate specificity for gelatins, collagens, and elastin (Keski-Oja et al., 1992). Because these plasminogen-independent proteolytic activities probably contribute to nerve outgrowth, an attenuation of these activities in the $\mathrm{uPA}-/-$ mouse might be detrimental to nerve regeneration.

Furthermore, uPA binds specifically to a cell surface receptor, namely the uPA receptor (uPAR) (Estreicher et al., 1989), which may activate intracellular signals necessary for regeneration. Although uPAR is glycosylphosphatidylinositol linked, it has been shown to convey intracellular signals via adapter molecules (Besser et al., 1996). Receptor-bound uPA activates Hck, a tyrosine kinase, in some monocytes, and in other monocytic cells lines, occupancy of the UPAR resulted in tyrosine phosphorylation of a $38 \mathrm{kDa}$ protein (Besser et al., 1996). uPAR has also been implicated in cell migration. On binding uPA, uPAR undergoes a conformational change mediated by bound-uPA. This conformational change exposes an epitope that activates tyrosine kinase, leading to a reorganized cytoskeleton and induced chemotactic activity in monocytes (Mondino et al., 1999). Similar effects were seen in rat smooth muscle cells, in which catalytically inactive receptor-bound uPA caused reorganization of the actin cytoskeleton, decreased stress fiber content, and led to changes in cell shape characteristic of motile cells, a process believed to involve tyrosine kinases and G-proteins (Degryse et al., 1999). Additionally, uPAR can regulate cell adhesion by direct interaction with vitronectin and $\beta_{1}$ and $\beta_{2}$ integrins. Cellular adhesion mediated by uPAR binding to vitronectin can be abolished by plasmin (Waltz et al., 1997). In contrast, uPAR interaction with $\beta_{1}$ and $\beta_{2}$ integrins suppresses integrin-dependent adhesion (Wei et al., 1996). Although uPAR is involved with localizing uPAdependent proteolytic activity to cell surfaces, this receptor can influence cell adhesion, induce cell migration, and convey intracellular signals. All of these functions may be necessary to support peripheral nerve regeneration.

uPA is also the major PA in spinal cord ventral horn motor neurons (Sumi et al., 1992; N. Seeds, unpublished observations). During embryonic development, an induction of uPA occurs in motor neurons concurrent with axonal outgrowth. Additionally, uPA activity increases in denervated muscle after sciatic nerve crush in mice (Hantai et al., 1990). Therefore, in the present study, regeneration of the motoneurons contributing to the crushed sciatic nerve was probably affected by the absence of uPA. uPA $-/-$ mice showed a considerable delay in eliciting motor responses (such as paw withdrawal and toe spread) when presented with test stimuli. We should note that although initial toe reflex recovery occurred relatively quickly, initial signs of recovery were scored by leg extension and not necessarily complete toe spreading. Thus, reinnervation of the lower leg may be enough to initiate the response we scored rather than complete reinnervation of the toe musculature.

Both tPA and UPA, independent of plasminogen, activate the growth factor HGF/SF (Mars et al., 1993). HGF/SF is a potent neurotrophic molecule for sensory neurons and a survival factor for motor neurons and promotes sympathetic neuron- and NGFdependent murine DRG axonal growth in culture (Yamamoto et al., 1997; Maina et al., 1998; Yang et al., 1998; S. Pu and N. Seeds, in preparation). $\mathrm{HGF} / \mathrm{SF}$ is also a mitogen for purified rat Schwann cells (Krasnoselsky et al., 1994). Although another activator, the HGF/SF activating protein, may be present in peripheral tissues, it also is a proenzyme requiring proteolytic activation (Shimomura et al., 1993). Thus, an absence of tPA- or uPA- dependent activation of $\mathrm{HGF} / \mathrm{SF}$ may attenuate its neuronal growth-promoting and Schwann cell mitogenic activities that are necessary for peripheral nerve regeneration.

In conclusion, this study showed that the lack of tPA, uPA, or plasminogen significantly increased the amount of time necessary to regain functional capabilities after peripheral nerve injury. These findings and the companion results (Siconolfi and Seeds, 2001), showing PA induction after peripheral nerve crush, provide insight into molecules that are required for successful peripheral nerve regeneration and suggest potential molecular mechanisms that may also facilitate CNS regeneration.

\section{REFERENCES}

Avellino A, Hart D, Dailey A, Mackinnon M, Ellegala D, Kliot M (1995) Differential macrophage responses in the peripheral and central nervous system during Wallerian degeneration of axons. Exp Neurol 136:183-198.

Azzouz M, Kennel P, Warter J, Poindron P, Borg J (1996) Enhancement of mouse sciatic nerve regeneration by the long chain fatty alcohol, $N$-Hexacosanol. Exp Neurol 138:189-197.

Besser D, Verde P, Nagamine Y, Blasi F (1996) Signal transduction and the uPA/u-PAR system. Fibrinolysis 10:215-237.

Brauer P, Yee J (1993) Cranial neural crest cells synthesize and secrete a latent form of transforming growth factor beta that can be activated by neural crest cell proteolysis. Dev Biol 155:281-285.

Carmeliet P, Collen D (1996) Targeted gene manipulation and transfer of the plasminogen and coagulation systems in mice. Fibrinolysis 10:195-213.

Carmeliet P, Schoonjans L, Kieckens L, Ream B, Degen J, Bronson R, De Vos R, van den Oord J, Collen D, Mulligan R (1994) Physiological consequences of loss of plasminogen activator gene function in mice. Nature 368:419-424.

Clark M, Zeheb R, White T, Bunge R (1991) Schwann cell plasminogen activator is regulated by neurons. Glia 4:514-528.

Degryse B, Resnati M, Rabbani S, Villa A, Fazioli F, Blasi F (1999) Src-dependence and pertussis-toxin sensitivity of urokinase-receptor dependent chemotaxis and cytoskeletal reorganization in rat smooth muscle cells. Blood 94:649-662.

Devor M, Govrin-Lippmann R (1979) Selective regeneration of sensory nerve fibers following nerve crush injury. Exp Neurol 65:243-254.

Eaton D, Scott R, Baker J (1984) Purification of human fibroblast urokinase proenzyme and analysis of its regulation by proteases and protease nexin. J Biol Chem 259:6241-6247.

Endo A, Nagai N, Urano T, Ihara H, Takada Y, Hashimoto K, Takada A (1998) Proteolysis of highly polysialylated NCAM by the tissue plasminogen activator-plasmin system in rats. Neurosci Lett 246:37-40.

Estreicher A, Wohlwend A, Belin D, Schleuning W, Vassalli J (1989) Characterization of the cellular binding site for the urokinase type plasminogen activator. J Biol Chem 264:1180-1189.

Fawcett J, Keynes R (1990) Peripheral nerve regeneration. Annu Rev Neurosci 13:43-60.

Glazner G, Lupien S, Miller J, Ishii D (1993) Insulin-like growth factor II increases the rate of sciatic nerve regeneration in rats. Neuroscience 54:791-797.

Glazner G, Morrison A, Ishii D (1994) Elevated insulin-like growth factor (IGF) gene expression in sciatic nerves during IGF-supported nerve regeneration. Mol Brain Res 25:265-272.

Gold L, Tostagno A, Frangione B, Passalaris T (1992) Localization of the cleavage sites on fibronectin following digestion by urokinase. J Cell Biochem 50:441-452.

Greenberg S, Lasek R (1988) Neurofilament protein synthesis in DRG neurons decreases more after peripheral axotomy than after central axotomy. J Neurosci 8:1739-1746.

Gutmann E, Guttmann L, Medawar P, Young J (1942) The rate of regeneration of nerve. J Exp Biol 19:14-44.

Hall S (1989) Regeneration in the peripheral nervous system. Neuropathol Appl Neurobiol 15:513-529.

Hantai D, Rao J, Festoff B (1990) Rapid neural regulation of muscle urokinase-like plasminogen activator as defined by nerve crush. Proc Natl Sci USA 87:2926-2930.

Hayden S, Seeds N (1996) Modulated expression of plasminogen activator system components in cultured cells from dissociated mouse dorsal root ganglia. J Neurosci 16:2307-2317.

Heiple J, Ossowski L (1986) Human neutrophil plasminogen activator is localized in specific granules and is translocated to the cell surface by exocytosis. J Exp Med 164:826-840.

Heussen C, Dowdle E (1980) Electrophoretic analysis of plasminogen activators in polyacrylamide gels containing sodium sulfate and copolymerized substrates. Anal Biochem 102:196-202.

Kalderon N (1984) Schwann cell proliferation and localized proteolysis: 
expression of plasminogen-activator activity predominates in the proliferating cell populations. Proc Natl Acad Sci USA 81:7216-7220.

Keski-Oja J, Lohi J, Tuuttila K, Tryggvason K, Vartio T (1992) Proteolytic processing of the 72,000-Da type IV collagenase by urokinase plasminogen activator. Exp Cell Res 202:471-476.

Kindzelskii A, Laska Z, Todd R, Petty H (1996) Urokinase-type plasminogen activator receptor reversibly dissociates from complement receptor type $3\left(\alpha_{\mathrm{m}} \beta_{2}\right.$, CD11/CD18) during neutrophil polarization. J Immunol 156:297-309.

Krasnoselsky A, Massay M, DeFrances M, Michalopoulos G, Zarnegar R, Ratner N (1994) Hepatocyte growth factor is a mitogen for Schwann cells and is present in neurofibromas. J Neurosci 14:7284-7290.

Krystosek A, Seeds N (1981) Plasminogen activator release at the neuronal growth cone. Science 213:1532-1534.

Krystosek A, Seeds N (1984) Peripheral neurons and Schwann cells secrete plasminogen activator. J Cell Biol 98:773-776.

Kung S, Lau H (1993) Modulation of the plasminogen activation system in murine macrophages. Biochem Biophys Acta 1176:113-122.

Lowry O, Rosenbrough N, Farr A, Randall R (1951) Protein measurement with the folin phenol reagent. J Biol Chem 193:256-275.

Maina F, Hilton M, Andres R, Wyatt S, Klein R, Davies A (1998) Multiple roles for hepatocyte growth factor in sympathetic neuron development. Neuron 20:835-846.

Mars M, Zarnegar R, Michalopoulos G (1993) Activation of hepatocyte growth factor by the plasminogen activators uPA and tPA. Am J Pathol 143:949-958

McGuire P, Seeds N (1990) Degradation of extracellular matrix by sensory neurons during neurite outgrowth. Neuron 4:633-642.

Mondino A, Resnati M, Blasi F (1999) Structure and function of the urokinase receptor. Thromb Haemost 82:19-22.

Munger J, Harpel J, Gleizes P, Mazzieri R, Nunes I, Rifkin D (1997) Latent transforming growth factor-beta: structural features and mechanisms of activation. Kidney Int 51:1376-1382.

Murphy G, Doherty J (1992) The matrix metalloproteinases and their inhibitors. Am J Respir Cell Mol Biol 7:120-125.

Navarro X, Verdú E, Buti M (1994) Comparison of regenerative and reinnervating capabilities of different functional types of nerve fibers. Exp Neurol 129:217-224.

Oblinger M, Lasek R (1988) Axotomy-induced alterations in the synthesis and transport of neurofilaments and microtubules in dorsal root ganglion cells. J Neurosci 8:1747-1758.

Odekon L, Blasi F, Rifkin D (1994) Requirement for receptor-bound urokinase in plasmin-dependent cellular conversion of latent TGFbeta. J Cell Physiol 158:398-407.

Perron J, Bixby J (1999) Distinct neurite outgrowth signaling pathways converge on ERK activation. Mol Cell Neurosci 13:362-378.

Quigley J, Gold L, Schwimmer R, Sullivan L (1987) Limited cleavage of cellular fibronectin by plasminogen activator purified from transformed cells. Proc Natl Acad Sci USA 84:2776-2780.

Raivich G, Kreutzberg W (1993) Peripheral nerve regeneration: role of growth factors and their receptors. Int J Dev Neurosci 11:311-324.

Rao N, Shi G, Chapman H (1995) Urokinase receptor is a multifunctional protein: influence of receptor occupancy on macrophage gene expression. J Clin Invest 96:465-474.

Rogister B, Delree P, Leprince P, Martin D, Sadzot C, Malgrange B, Munaut C, Rigo J, Lefebvre P, Octave N, Schoenen J, Moonen G (1993) Transforming growth factor $\beta$ as a neuronoglial signal during peripheral nervous system response to injury. J Neurosci Res 34:32-43.

Saksela O, Rifkin D (1990) Release of basic fibroblast growth factor- heparin sulfate complexes from endothelial cells by plasminogen activator-mediated proteolytic activity. J Cell Biol 110:767-775.

Schafer B, Maier K, Eickhoff U, Todd R, Kramer M (1994) Plasminogen activators in healing human wounds. Am J Pathol 144:1269-1280.

Seeds N, Friedman G, Hayden S, Thewke C, Haffke S, McGuire P, Krystosek A (1996) Plasminogen activators and their interaction with the extracellular matrix in neural development, plasticity and regeneration. Semin Neurosci 8:405-412.

Shetty S, Kumar A, Johnson A, Pueblitz S, Holiday D, Raghu G, Idell S (1996) Differential expression of the urokinase receptor in fibroblasts from normal and fibritic human lungs. Am J Respir Cell Mol Biol 15:78-87.

Shimomura T, Kondo J, Ochiai M, Naka D, Miyazawa K, Morimoto Y, Kitamura N (1993) Activation of the zymogen of hepatocyte growth factor activator by thrombin. J Biol Chem 268:22927-22932.

Siconolfi L, Seeds N (1998) Induction of the plasminogen activator system during sciatic nerve regeneration. J Neurochem 70 [Suppl 1]:65.

Siconolfi L, Seeds N (2001) Induction of the plasminogen activator system accompanies peripheral nerve regeneration after sciatic nerve crush. J Neurosci 21:4336-4347.

Sievers J, Hausmann B, Unsicker K, Berry M (1987) Fibroblast growth factors promote the survival of adult rat retinal ganglion cells after transection of the optic nerve. Neurosci Lett 76:157-162.

Son Y, Thompson W (1995) Schwann cell processes guide regeneration of peripheral axons. Neuron 14:125-132.

Sumi Y, Dent M, Owen D, Seeley P, Morris R (1992) The expression of tissue and urokinase-type plasminogen activators in neural development suggests different modes of proteolytic involvement in neuronal growth. Development 116:625-637.

Tetzlaff W, Zweirs H, Lederis K, Cassar L, Bisby M (1989) Axonal transport and localization of B-50/GAP-43-like immunoreactivity in regenerating sciatic and facial nerves of the rat. J Neurosci 9:1303-1313.

Torigoe K, Tanaka H, Takahashi A, Awaya A, Hashimoto K (1996) Basic behavior of migratory Schwann cells in peripheral nerve regeneration. Exp Neurol 137:301-308

Tyagi S, Lewis K, Pikes D, Marcello A, Mujumdar V, Smiley L, Moore C (1998) Stretch-induced membrane type matrix metalloprotease and tissue plasminogen activator in cardiac fibroblast cells. J Cell Physiol 176:374-382

Van der Zee C, Nielander $H$, Vos J, Lopes da Silva S, Verhaagen J, Oestreicher A, Schrama L, Schotman P, Gispen W (1989) Expression of growth-associated protein B-50 (GAP43) in dorsal root ganglia and sciatic nerve during regenerative sprouting. J Neurosci 9:3505-3512.

Verdú E, Navarro X (1997) Comparison of immunohistochemical and functional reinnervation of skin and muscle after peripheral nerve injury. Exp Neurol 146:187-198.

Waltz D, Natkin L, Fujita R, Wei Y, Chapman H (1997) Plasmin and plasminogen activator inhibitor type 1 promote cellular motility by regulating the interaction between the urokinase receptor and vitronectin. J Clin Invest 100:58-67.

Wei Y, Lukashev M, Simon D, Bodary S, Rosenberg S, Doyle M, Chapman H (1996) Regulation of integrin function by the urokinase receptor. Science 273:1551-1555.

Yamamoto Y, Livet J, Pollock R, Garces A, Arce V, deLapeyriere O, Henderson C (1997) Hepatocyte growth factor (HGF/SF) is a musclederived survival factor for a subpopulation of embryonic motoneurons. Development 124:2903-2913.

Yang X, Toma J, Bamji S, Belliveau D, Kohn J, Park M, Miller F (1998) Autocrine hepatocyte growth factor provides a local mechanism for promoting axonal growth. J Neurosci 18:8369-8381. 